University of Wollongong

Research Online

University of Wollongong in Dubai - Papers

University of Wollongong in Dubai

$1-1-2012$

\title{
University of Wollongong in Dubai: creating a private university in the public
} interest

Robert Whelan

University of Wollongong in Dubai, rob@uow.edu.au

Daniel Kratochvil

Univeristy of Wollongong in Dubai, dkratoch@uow.edu.au

Follow this and additional works at: https://ro.uow.edu.au/dubaipapers

\section{Recommended Citation}

Whelan, Robert and Kratochvil, Daniel: University of Wollongong in Dubai: creating a private university in the public interest 2012, 97-111.

https://ro.uow.edu.au/dubaipapers/173

Research Online is the open access institutional repository for the University of Wollongong. For further information contact the UOW Library: research-pubs@uow.edu.au 


\title{
UNIVERSITY OF WOLLONGONG IN DUBAI: Creating a Private University in the Public Interest
}

\begin{abstract}
About the Authors
Professor Rob Whelan was appointed President of the University of Wollongong in Dubai in August 2008. He was previously Dean of Science (2002-08) and Head of the School of Biological Sciences (1993-2002) at the University of Wollongong in Australia. As Dean, he established an innovative International Science Degree in which students at Universities in Colorado, Dublin and Wollongong work together in the same degree program. He is the author of a research monograph, The Ecology of Fire (Cambridge University Press 1995), has supervised over 20 doctoral students, has published well over 100 scientific papers and attracted A $\$ 2.8$ million in competitive research grant funding. He was Vice President of the Ecological Society of Australia and editor of its professional journal, Austral Ecology. Since his appointment at UOWD, Professor Whelan has established the University's Faculty structure, stimulated research activity and doctoral programs, and broadened the University beyond business and IT, into Engineering and the Social Sciences.
\end{abstract}

Dr Daniel Kratochvil heads the Office of Institutional Effectiveness at UOWD. Previously, he served as a senior administrator at universities in Bahrain, Abu Dhabi and Dubai in addition to teaching courses in the fields of philosophy, architecture, history, political science, and sociology. Prior to moving to the Gulf, he worked in New York City at the Council for International Education Exchange as well as projects for the Freedom Forum at Columbia University and the Mellon Foundation. His research interests are in the field of international higher education, with a focus on governance issues and relations between home and satellite campuses. Extending from his doctoral dissertation, he is continuing research on federal systems and intergovernmental relations. He holds a Bachelor of Arts Degree from the University of Texas in Austin; and, a Master of Arts, Master of Philosophy, and Doctor of Philosophy from Columbia University in the City of New York.

This case was written by Dr Rob Whelan and Dr Daniel Kratochvil at the University of Wollongong in Dubai. It was prepared using company information and interviews and its intention is to provide material for class discussion through publication. The authors do not intend to illustrate either effective or ineffective handling of a managerial situation. The authors may have disguised certain names and other identifying information to protect confidentiality. 


\section{UNIVERSITY OF WOLLONGONG IN DUBAI: Creating a Private University in the Public Interest}

Professor Rob Whelan was appointed President of the University of Wollongong in Dubai (UOWD) in August 2008, moving from the University of Wollongong in Australia (UOW) where he held the position of Dean of Science. The expectation at the time of his appointment was that he would consolidate previous developments, improve governance and operational procedures, and review the organisational structure.

Through its development, UOWD had followed the common model for branches of universities in the UAE, concentrating on business programs with a lesser emphasis on computer science and IT. Academic staff had been encouraged to maintain some research activity in line with the university's particular focus on masters-level programs. The primary driver of the university's activities had always been student numbers, due to the fact that it is a private institution without financial support from local benefactors. As a result, tuition fees were the only way of funding both day-to-day operations and new developments.

Rob Whelan brought to the job in Dubai the perspective that public-good benefits flow from a comprehensive institution connected with the larger community and these are led by academic staff who are actively engaged in research with outcomes that serve the national interest. Even before arriving in Dubai, he was exploring the possibility of applying aspects of this model to UOWD and considering the scope of changes needed to achieve this at a private institution. Central questions were: Should a research focus be pursued by a private institution in the UAE? Could it be pursued in a way that was compatible with growth in student numbers and the maintenance of financial viability? Would current staff be willing to pursue such an agenda? To what extent would they be prepared for the challenges embedded in it? What would be the reaction of other stakeholders? How should such a change in direction be implemented?

This case explores the various processes through which a new leader takes stock of an existing institution, identifies the potential for development in a particular direction, draws upon a range of stakeholders to refine the vision and develop it into a strategic plan, gains support for the plan, and then implements change through close collaboration with the institution's constituents.

\section{University of Wollongong in Dubai}

In 1993, the "Institute for Australian Studies" was established in Dubai - the first operation to be set up in the UAE by a foreign university. It was an initiative of a private company, ITC Ltd $^{1}$, on behalf of the University of Wollongong in Australia. ITC was responsible for the management of the new institution and therefore set the annual budget targets and had direct control of budgetary processes and operations. Some of the management systems in the Dubai operation come from ITC (e.g. Human Resources and Finance systems) and the ITC focus has been on growth in its investment, measured by student enrolments.

\footnotetext{
${ }^{1}$ http://www.itc.com.au
} 
Academic support for the university's development in Dubai came directly from the University of Wollongong, through access to the full range of library resources, curricula for new courses, some funding for joint research activities and curriculum development, and regular academic program review. As the new institution grew and developed, it became a key contributor to the strategic goals of the University of Wollongong in the area of internationalisation.

When the Institute for Australian Studies was established, there was no higher education bureaucracy, although there was a Minister, His Excellency Sheikh Nahayan Mubarak al Nahayan. Within six years of its establishment, the Dubai institution had grown to 400 students and was granted a license by the UAE Ministry of Higher Education and Scientific Research to operate as a branch campus of the University of Wollongong, Australia. In July 2003, the UOW Dubai Campus was re-named the University of Wollongong in Dubai (UOWD) and moved to its current location in Knowledge Village.

By the time UOWD moved, the UAE Ministry had developed standards for university licensure that required foreign-based institutions to operate as independent entities. The University of Wollongong - Dubai Campus was therefore transformed into UOWD, with its own Board of Trustees. This independent institution nevertheless retained close connections with the University of Wollongong in Australia, including the ability to transfer degrees between the institutions, a cooperative quality assurance process, and involvement of UOWD in the regular audits by the Australian University Quality Agency.

When Rob was appointed, research activity by UOWD academic staff and the recognition of their research contributions was already becoming integrated in the university's culture. In January 2004, a UOWD Research Newsletter was launched and the following month the University Research Committee was created. In 2006, three research awards were introduced to recognise accomplishments of UOWD academic staff: a Research Excellence Award, a Best Paper Award, and a Research-Teaching Nexus Award. A UOWD Research Grants Scheme was introduced to encourage the research activities of the teaching staff at the University through limited financial support.

By 2011, the University of Wollongong in Dubai has a stable student population of approximately 3,000 students, about equally distributed among undergraduate and postgraduate degree programs, plus another 900 students enrolled in preparatory and English language classes. It has nearly 200 staff, over 50 of them involved in teaching academic programs. It is a multicultural institution, with nearly 100 nationalities among its students and over 30 among the staff. The Board of Trustees includes the Vice Chancellor and Deputy Vice Chancellor (International) of UOW, the CEO of ITC, a member of the ITC Board, the UOWD President, and UAE community representatives. Through a quality assurance agreement with UOW, and a joint review process, UOWD maintains the equivalency of academic programs at the two campuses.

\section{Higher Education in the UAE - the Environmental Context}

When UOWD started in 1993, there was no competition in the UAE from private institutions of higher education. From that time, the market changed enormously, with forty-eight universities and colleges in Dubai alone by 2011. Although these institutions are of varying sizes, they are 
generally small (fewer than 1,000 students, with a significant number having fewer than 100 students) and their offerings are restricted to a limited set of academic disciplines, the most common being business, IT and engineering. In addition to the public, national institutions of the United Arab Emirates University, Zayed University and the Higher Colleges of Technology, most of the larger and well-established universities and colleges in the UAE have local benefactors, which serve to ground them in the local environment and provide resources for development.

Approximately half of the higher education institutions in Dubai are licensed by the federal government through the Ministry of Higher Education and Scientific Research ${ }^{2}$. To ensure high international standards, the Ministry undertakes thorough reviews of each academic program offered by a licensed institution by means of External Review Teams, made up of overseas experts in the relevant field. National licensure of the institution ensures that its degrees can be attested by the UAE Ministry, which is generally required for employment in government agencies.

The UAE Ministry's requirements can be avoided by branch campuses of foreign institution through choosing to locate in one of several "free zones" in the Emirate. These institutions are subjected instead to the requirements of the 'University Quality Assurance International Board' (UQAIB), which assesses the equivalence between the Dubai operation and the home campus in the delivery of programs and the effectiveness of arrangements for quality assurance. As part of this agency's streamlined accreditation process, individual degree programs are not subject to review. Several institutions that maintain UAE Ministry of Higher Education and Scientific Research licensure, such as UOWD and the British University in Dubai, happen to be located in free zones but are not assessed by AQAIB because of their national licensure and national program accreditation.

The large number of regulatory bodies and licensing and accreditation systems makes for a complex higher education landscape, creating challenges both for long-term players, such as UOWD, and also for new entrants to the market. Over the past decade, several new operations have foundered within several years of launching. Jason Lane, a Fulbright fellow working in the UAE in 2009-10, has described this complexity and assessed its implications for maintaining quality in higher education in Dubai. ${ }^{3}$

\footnotetext{
${ }^{2}$ See UAE Commission for Academic Accreditation portal: http://www.caa.ae

${ }^{3}$ Lane, J.E. (2010) International Branch Campuses, Free Zones, and Quality Assurance: Policy Issues for Dubai and the UAE, Dubai School of Government Working Papers, http://www.dsg.ae/PUBLICATIONS/PublicationDetail.aspx?udt_826_param_detail=2393; Lane, J.E. (2011) Importing private higher education: International branch campuses. Journal of Comparative Policy Analysis, 13, 367-381; Lane, J.E. (2010) Private higher education in Dubai: Growing local versus importing local campuses. Chapter 5 in Kinser, K. et al. (eds), The Global Growth in Higher Education. ASHE Higher Education Report, 36(3).
} 


\section{Creating a Private, Research-Active University in the UAE}

\section{Exploration}

The first question explored by Rob, even before leaving Wollongong for the UAE, was whether UOWD could be expanded into a more comprehensive university (that is, covering a broad range of disciplines) with a greater emphasis on research.

It was obvious that UOWD delivered only a very small subset of the programs offered at the University of Wollongong in Australia and there was plenty of opportunity within the existing agreements between the institutions to expand both undergraduate and postgraduate programs. A broadening of UOWD's undergraduate programs would attract more students to the new fields of study, both as major topics of study and as an enriching diversity of elective subjects for the existing degree programs. Meanwhile, a greater array of postgraduate programs at UOWD would hold great potential for training professionals in Dubai in a variety of specialized fields to fill niches in the country's labour market.

In the research area, the lack of doctoral level education in UAE-based institutions was surprising, given that many senior Emiratis working in government obtained doctorates overseas, and doctoral degree graduates are obviously well respected. Was there a possibility that UOWD could become the first private university to offer a $\mathrm{PhD}$ ? This would have obvious reputational benefits within the UAE and would also facilitate research by the academic staff, thereby augmenting the student experience at all levels. There were three main motivations for wanting to develop research at UOWD:

(i) Research is a key element of any credible University - ensuring that teaching is at the forefront of knowledge and that students interact with active researchers;

(ii) University-based research and research training is an important component of contributing to national needs in research, because government-based funding for $\mathrm{R} \& \mathrm{D}$ is very restricted and support for research from the private sector virtually nonexistent;

(iii) Facilitating university-based research and having and active doctoral program would overcome two of the greatest impediments to recruiting high quality staff from western countries: a lack of opportunity for personal research development and for creating an active group of research students.

Rob first held preliminary discussions with academic staff and senior administrators at the University of Wollongong in Australia, especially those who had had previous experience with the Dubai operation, to explore which new degrees could be offered readily in Dubai, based on the alignment of University of Wollongong curricula with statements about the needs for human capital development in the UAE that were contained in various strategic planning documents. ${ }^{4}$

\footnotetext{
${ }^{4}$ Abu Dhabi Economic Vision 2030 - www.adbic.ae/downloads/EconomicVision2030.pdf; Dubai Strategic Plan 2015 - http://www.dubai.ae/opt/CMSContent/Active/Shared/Files/DEG_docs/Dubai_Strategic_Plan_2015.pdf; UAE Government Vision 2021 - http://www.vision2021.ae
} 
Upon arriving in Dubai, Rob began to investigate these options by reviewing the existing resources at UOWD - staff, infrastructure, students, and market position. Consultation with the existing leadership of UOWD included a thorough review of the strengths and weaknesses of the University and its position in the local market. One important part of this process was testing his initial assessment of the many competing institutions in terms of perceived quality, degrees offered, accreditation standing, and other value propositions. Another was understanding the financial position of UOWD at that time: by mid 2008, student numbers, revenue and profit all looked likely to exceed the budget targets for that year by a considerable margin, making this a most opportune time for investment in new initiatives.

Professor Whelan researched a wide range of higher education institutions in UOWD's main catchment areas of Dubai, Abu Dhabi and Sharjah, based on information on web sites of the Dubai Knowledge and Human Development Authority (KHDA) ${ }^{5}$, the UAE Commission for Academic Accreditation (CAA) ${ }^{6}$ and the institutions themselves. He visited the CEOs of six of them during his first two months in the job: American University of Sharjah, University of Sharjah, American University of Dubai, British University of Dubai, Skyline College, and the Higher Colleges of Technology.

It became clear that most of the UAE private universities, especially the branch campuses located in Dubai free zones, were indeed focussing on a restricted range of business programs and there were few competitors at the 'upper end' of the quality spectrum. Moreover, these institutions generally concentrated on either undergraduate or postgraduate education, but not both. Those focussing at postgraduate level were typically smaller branch campuses offering a limited number of business degrees, usually the MBA. In contrast, the larger private institutions focussed on undergraduate programs. The larger, more comprehensive institutions were generally non-for-profit and had close connections with Emirati owners or sponsors who contributed land, buildings, direct funding or less tangible support.

Discussions with Professor Badr Aboul-Ela, the head of the agency responsible for overseeing licensure and accreditation within the Ministry of Higher Education and Scientific Research (the CAA), led to the conclusion that institutions were encouraged to focus on programs that were in the national interest and were aligned with local needs. "Do we really need any more MBA programs in the UAE?" was Professor Badr's assessment. He also explained that, through their Standards, the CAA was setting threshold requirements for the quality of curricula, academic staff qualifications, and workloads, based on the expectation that all teaching staff would be research-active.

The market also showed a conspicuous absence of doctoral programs, with a Doctor of Education at the British University in Dubai being the only one offered by a private institution in early 2010. Even the large and comprehensive national University, UAE University, lacked a doctoral program until their PhD was established in 2010. Discussions with members of the professional community led Rob to the realization that many Emiratis with senior positions in government and the private sector had obtained their doctorates at overseas institutions but there was interest in the opportunity for undertaking doctoral studies within the UAE. Further review of the possibility of a doctoral program suggested the strong possibility of such a program

\footnotetext{
${ }^{5}$ KHDA - http://www.khda.gov.ae/en/default.aspx
}

${ }^{6}$ CAA - http://www.caa.ae 
becoming self-funding quite rapidly after initial investment in hiring faculty members. Additional elements of the equation were the reputational enhancement and publicity that would derive from becoming the first private university with a doctoral program in business, in addition to the indirect but tangible benefits for attracting high-performing students into the University's undergraduate and masters programs.

The indications contained in the various UAE Strategic Planning statements that there was to be greater national focus on R\&D was reinforced in discussions Rob held with a number of government officials. They confirmed that there was a growing appreciation of the need for government investment in moving to a 'knowledge-based economy'. There has been an increasing realisation in the UAE that R\&D funding was being neglected and the proportion of GDP devoted to R\&D was much smaller than in western countries - as little as $0.5 \%$, with very little contributed by the private sector. ${ }^{7}$

An important played in this development was Dr Ken Wilson, who had recently been appointed Director of the newly established National Research Foundation $(\mathrm{NRF})^{8}$, created with the vision of being the UAE's counterpart to overseas agencies such as the US National Science Foundation, the Australian Research Council, and the Science Foundation of Ireland. NRF was planning to initiate a project-based grants competition to promote research of international standard to be conducted by staff in nationally licensed institutions. The proposed funding arrangements were to include an overhead to be paid to institutions hosting NRF-funded projects, thus providing an income stream for supporting the development of a research infrastructure in the sector.

Funding options for research in higher education institutions in the UAE were therefore on the horizon. To participate in this exciting development in the region, the University would have to position itself by making its own investment to develop the capacity of the academic staff to engage in research related activities. Rob reasoned that such an investment would need to include staff recruitment, staff professional development, increased direct funding in the form of research grants and conference support, creating of research groups of critical mass, and teaching release to free up some time for the research-active staff. With this preparation, UOWD would be ready to capitalise on future government-based funding streams for research.

\section{Decision}

As a result of his investigations of the UAE environment, the university and the major stakeholders, Rob concluded that broadening the numbers of disciplines offered at UOWD was the best option for meeting both the local expectations of accredited institutions and also for expanding the institution's revenue base through new student markets. He also concluded that the pursuit of research should indeed be compatible with growth in student numbers and therefore financial viability. While the initial stages would require an investment in human capital, the returns in the medium to long term would be substantial. In fact, Rob was convinced that there was a window of opportunity available that must be exploited, or else UOWD would

\footnotetext{
${ }^{7}$ http://unesdoc.unesco.org/images/0015/001541/154139e.pdf

${ }^{8}$ http://www.nrf.ae
} 
fall behind its key competitors and lose its preeminent position in the increasingly competitive UAE higher education market.

\section{Implementation Part 1: Development of a new Strategic Plan}

Having decided on the general direction for the University, Rob turned to the question of how to best implement the planned changes in a manner that would maximise the cooperation of shareholders and stakeholders. The decision was made to drive the change through a strategic planning process.

Effective implementation was going to need a strong leadership team and the appropriate academic structure within the University. The first step taken was the creation of disciplinebased Faculties from the previously separate undergraduate and postgraduate Colleges. This restructure produced the the discipline-based groupings of academic staff that would be required to create the critical mass that is so important for peer interactions in research. The new discipline-based Faculty structure was also expandable, so new disciplines could be readily added in the future. Deans were appointed to each Faculty and discussions held with them to confirm that their academic staff were willing to embark on the new path for the University.

The decision was made to drive the change through the strategic planning process and therefore treat research enhancement as an integral part of the University's overall development. A major review of the University's existing strategic plan (2008-12) was launched at an All-Staff Forum in July 2009. Staff members from across the university were invited to provide responses to the presentation and therefore have an input to the revision of the Vision, Mission, Goals and Values of the University. Responses were sought through committees (Research, Education, Academic Board, Faculties) as well as through individual written comments as drafts evolved. The various components of the developing plan were displayed for all staff to comment on (Exhibit 1). This approach was seized with enthusiasm by the staff, with many insightful comments and constructive suggestions made. The final outcome was collated and presented back to the staff at another All-Staff Forum in September 2009.

With the assistance of a consultant serving as facilitator, the draft Strategic Plan that emerged from the extensive consultation process was discussed in each faculty and administration department, to ensure that the Deans and Managers of Administrative Departments translated the 3 -year goals and objectives into their annual operational plans. Once the elements of the strategic plan had been embedded into the functional targets of each faculty and department, the Office of Institutional Effectiveness developed quantitative and qualitative performance indicators for assessing progress towards achieving each objective.

The new 2010-12 Strategic Plan included major goals on growing and positioning the university, high quality teaching and learning, internationalisation, community engagement, human capital development, and the development of efficient systems. Importantly, enhancement of research emerged from the review as a key plank in the new plan (Exhibit 2).

The new strategic plan was communicated with the Australian stakeholders, UOW and ITC, through informal discussions at senior executive level and through formal committee approval processes in early 2010. The draft plan was discussed in those UOWD committees that had 
members representing both UOW and ITC, and approved by the UOWD Board of Trustees. The new strategic plan formed the basis of UOWD's contribution to the consolidated 2010 plan of the ITC group and the goals, objectives and strategies in the plan define UOWD's actions listed in the annual ITC Operations Plan.

Exhibit 1: Staff responses to draft statements of the university's vision, mission, values and goals, made over a 1-month period, were comprehensive and constructive.

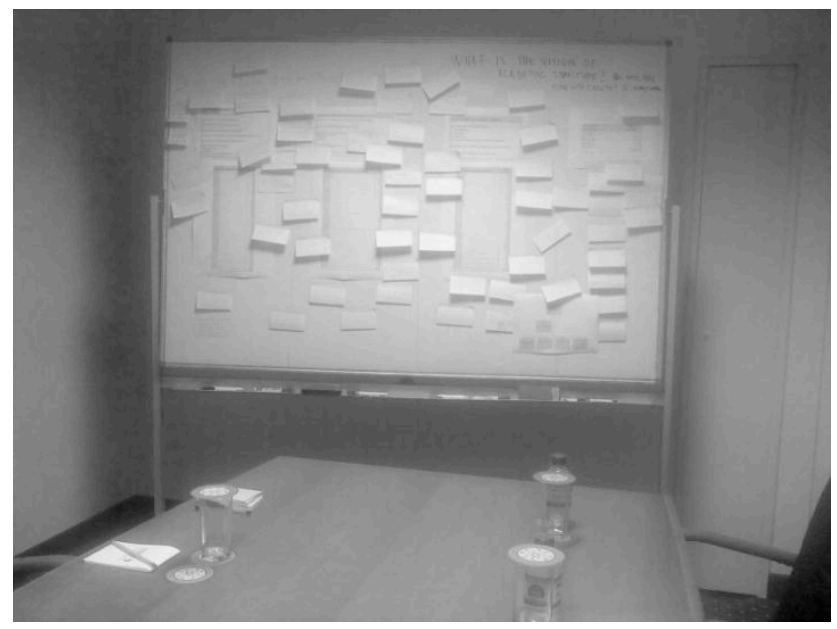

Exhibit 2: Research Goal and key objectives in the 2010-12 UOWD Strategic Plan

\section{GOAL 3 - Research and Research Training}

To engage in high-quality research with outcomes that will benefit the region, and to have effective programs for research training.

\section{OBJECTIVES}

1. Strong leadership of research strategy and processes

2. Increase the university's overall research activity and research output

3. Increase the numbers of applications for external grants

4. Establish doctoral programs in each Faculty and recruit strong doctoral students aligned with research strengths 


\section{Implementation Part 2: Engagement with the Plan}

The staff represent only one stakeholder group in a university and there are many communication pathways within any institution - both formal and informal. The new direction for UOWD was therefore communicated to a range of stakeholders in a number of ways:

- Several All-staff Forums were held within the University, as described above. In addition, discussions of the strategic direction were embedded within university committee meetings, workshops on enhancing research performance and writing grant proposals, and workshops on a new performance appraisal process for academic staff.

- Closer engagement was created between the UOWD Senior Executive with the SRC (Student's Representative Council), including the hosting by the President of a 'SRC Majlis' meeting in early 2010;

- Some groups of students were involved even more deeply through discussions in their classes, including a lecture on 'change management' by the President to a foundation class in business, in 2009, using UOWD as the case study, a project on 'value propositions' of UOWD's various degree programs in a senior undergraduate class in marketing in 2010, and the inclusion of a critique of the UOWD new strategic plan as an assignment in the Master of Strategic HR Management program in 2011;

- The President included an overview of the strategy in his addresses at UOWD information sessions and new student orientation days each semester, and at the annual UOWD prize-giving event;

- Information sessions promoting UOWD were held in several Emirates, with strong messages about UOWD's development and aspirations as an integral part of the presentations;

- The speeches surrounding the conferring of an Honorary Doctorate on the Minister of Higher Education and Scientific Research, Sheikh Nahayan Mubarak al Nahayan, at the June 2009 graduation ceremony focussed on the alignment of UOWD's approach with national needs;

- A 'Meet the President' function for the alumni was held in March 2010', at which the new blueprint for UOWD's development was presented, especially the development of the doctoral programs;

- All public events were well publicised by the UOWD Marketing Department in press releases, interviews and marketing materials.

- The UOWD Senior Executive supported helped fund the development of a UOWD Alumni Group publication 'Stay Connected' in early 2010 and the President's message in the very first issue was used to highlight the new directions (Exhibit 3);

- The UOWD Research Committee's 6-monthly newsletter, SCHOLAR, which is widely circulated to industry, government agencies and other tertiary institutions, was used to highlight the greater research aspirations and other proposed changes; ${ }^{10}$

\footnotetext{
${ }^{9}$ http://www.uowdubai.ac.ae/news/index.php?action=view\&id=438

${ }^{10}$ http://www.uowdubai.ac.ae/research/newsletters/scholar_4_2.pdf
} 
- The President and Vice President (Academic) made presentations at the first meetings in 2010 of the newly established Faculty Advisory Committees, which comprise industry, community and government representatives relevant to each discipline, charging them with the responsibility of focussing on strategic directions for each Faculty;

- Focus group sessions were conducted with industry representatives as proposals for doctoral degrees and other new programs were being developed;

- Presentations featuring the University's goals and strategies were made to External Review Teams of the Commission for Academic Accreditation during their program accreditation visits to the campus.

There is ample evidence that these communication strategies had an impact outside the University, as well as within. For example, at a recent graduation ceremony, the Australian Ambassador to the UAE and Qatar, His Excellency Doug Trappett, described the booming UAEAustralia relations and the goodwill between the two countries, and added: "I am proud to say that the University in Wollongong in Dubai has played a central role in boosting relations between UAE and Australia, as proved by the emergence of 'quality ambassadors' from this institution, including over 700 Emirati graduates." He added: "I am happy to note that the university is now venturing into high-end research which will further contribute to the progress of the UAE." 11

Moreover, in the 2011 report of the Australian Universities Quality Agency (AUQA) on their audit of the University of Wollongong ${ }^{12}$, the following comments were made about UOWD:

"The President of UOWD, a former dean at UOW, has a firm vision for UOWD, involving greater breadth and depth of academic activities. The UOWD Strategic Plan outlines the elements of this vision and how it will be achieved. Since the 2006 AUQA Audit Report, UOWD has expanded its suite of offerings: a degree in engineering is in the process of being accredited in the UAE and the University has started to offer PhD and Doctor of Business Administration programs. This expansion of operations has been accompanied by a restructure of academic operations into three faculties under the leadership of new deans. AUQA finds these developments to be positive and appropriate..."

A critical question, however, is whether the shift in emphasis for UOWD's direction has had the intended impact. At the time of writing, it is too early to say whether there will be an impact on overall student demand for places in UOWD's programs. However, there are some early signs of success. For example, there were 750 expressions of interest for 30 places in the first intake of the doctoral program in late 2010 , and about $60 \%$ of these were from UAE Nationals.

\section{A Year Later}

The strategy described above has been highly successful within the UAE. However, several key challenges remain. Some of these might have been foreseen and better strategies or contingency plans put in place at an earlier stage.

\footnotetext{
${ }^{11} \mathrm{http} / / /$ www.uowdubai.ac.ae/pdfs/graduation/20110411_Australian_Ambassador-verbatim.pdf

${ }^{12}$ http://www.auqa.edu.au/files/reports/auditreport_uow_2011.pdf
} 
First, funding to support the NRF project grants program had not materialised, even three years after the creation of the NRF, so the sole source of significant amounts of competitive grant funding in 2009, 2010 and 2011 was the Emirates Foundation - a philanthropic organization created by the government of Abu Dhabi (http://www.emiratesfoundation.ae), with a rather limited funding pool to disburse. The Emirates Foundation does not provide an overhead to the University; instead, it requires a financial contribution from the university hosting a successful grant. As a result, there is no immediate prospect of an income stream to universities based on research activity.

Second, modifications to policies on conference travel, internal research grants and the research excellence award have been paralleled by an increase in the numbers of refereed publications and an increase in the numbers of academic staff publishing: from 30 papers by 14 staff in 2008, when the first changes in emphasis were made, to 46 papers by 31 staff in 2009, to 59 papers by 35 staff in 2010. However, the shift to a stronger research culture carries with it the risk of disenfranchising strong teaching staff who have limited research aspirations or experience, and were appointed at a time when these were not expectations. While this is a problem in many institutions worldwide, it is heightened in the developing higher education environment of the UAE. In response, UOWD is now working on the development of promotions systems that will recognise these staff and their contribution to the institution, while at the same time providing the professional development needed to hone their research skills.

Third, the rapid pace of development at UOWD created some nervousness within the University of Wollongong. There is a perception of a risk of reputational damage to the parent institution if problems are experienced by UOWD in the complex and changing UAE higher education environment. This concern needs to be managed to ensure that there is no lessening of engagement between the two institutions at an academic level. Enhanced interactions are needed to identify and develop appropriate new UOWD programs and support further initiatives.

Fourth, communication with the Australian-based stakeholders was essentially restricted to formal approval processes for the strategic plan, through ITC committees and the UOWD Board of Trustees (which includes members from both the University of Wollongong in Australia and ITC). This limited level of engagement is unlikely to create strong support for initiatives that require investment and therefore have an immediate impact on profitability, even if there is a good prospect of long term benefits. This problem was exacerbated by the slowing of growth in student numbers after 2008, as a result of the Global Financial Crisis. 


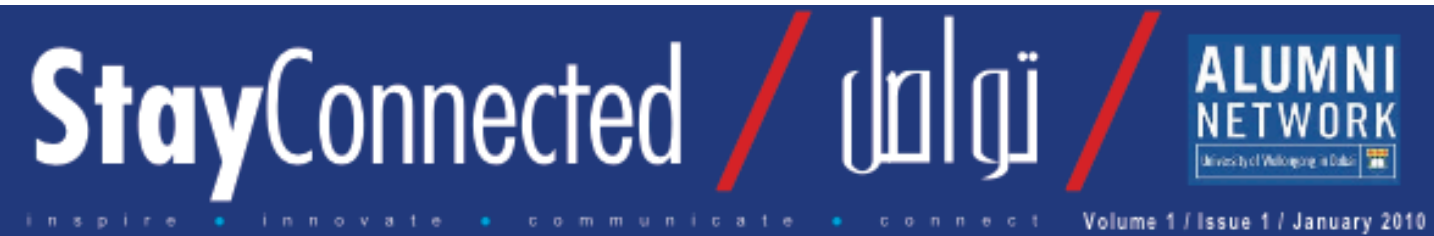

\section{From the President's Desk}

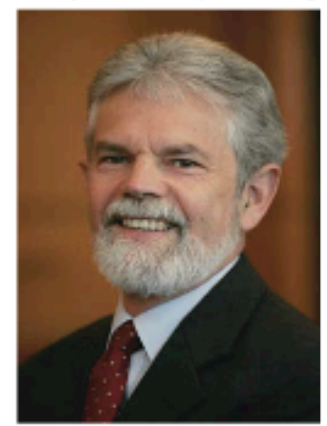

Congratulations to the UOWD Alumni on the launch of this very first issue of 'Stay Connected'

Mary this be the start of a long-lived and effective venture that will heip you, our graduates, to maintain their connec tions with each other, and with all parts of the University both current students and staff.

One of my first rewarding experiences as the new President of UOWD, soon after I was appointed in September 2008 was meeting the Heads of a number of government depart ments in Dubai. Without exception, at each visit I was greeted by at least one member of staff of the organization who said: "Hello, I'm one of yours." I soon came to realize that our graduates are everywhere!

However, in the past we have not been very good at keeping track of our alumni - nor very good at helping you to keep in touch with each other and with the University. UOWD, which is the longest established private University in the UAE, has a very large alumni body - over 4,500 graduates over the years since we started with 8 students in 1993. You have a high quality degree from a well established, nationally accredited University in the UAE, which has strong links with the University of Wollongong - one of Australia's top universities. Many of you now hold senior, responsible positions in commerce, industry and government in the UAE and in other countries.

The alumni can and should play a very important role in any University. As UOWD alumni, you can help your University by giving us the benefit of your good ideas and opinions, by providing us with contacts to help with new initiatives, by giving current students opportunities for volun tary and paid work experience, by telling us what we might do to help you further - in your current career. To make it easy for you to do any of these things, we need you to stay connected. I am therefore very pleased indeed to see a number of initiatives aimed at helping us to 'stay connected' with our alumni. There's a Facebook site, there is a series of monthly 'Alumn Network' seminars, and we are building our alumni database. I would like to pay tribute to Ms Sherri Van Over for devoting her time, energy and care to these activities.

This 'Stay Connected' newsletter is a great initiative, which will complement the other activities for our alumni. I hope you will all make the most of it as a way to find out about UOWD's plans and aspirations, about recent and upcoming events at the University, about recent achievements of our staff and students - and, above all, about what other alumni are doing in their lives

I finish by giving you a brief summary of the new initiatives the University is currently working on As you may have seen in the media, we have developed a Doctor of Business Administration program and a PhD program, which we hope will be accredited in time to take our first doctoral students in September 2010. This will be another first for UOWD! We will soon finalize the accreditation of a Bachelor of Engineering program, with specializations in Electrical, Computer and Telecommunication Engineering -again, we hope this will start in 2010. We have been reviewing and revising the curriculum for our highly successful MQM program, and will soon introduce a number of specializations to address particular needs in the UAE - including such areas as health, education, security.

As we have so many research-active staff in the various business management fields, we are also working to develop UOWD as a centre for developing and publishing business cases especially cases that are relevant to the GCC region. Our staff are also strong players in severa recently established research grant schemes, such as the Emirates Foundation and the National Research Foundation.

Perhaps these few comments will give you a taste for what is to come! All the best with the newsletter... and please 'Stay Connected"?
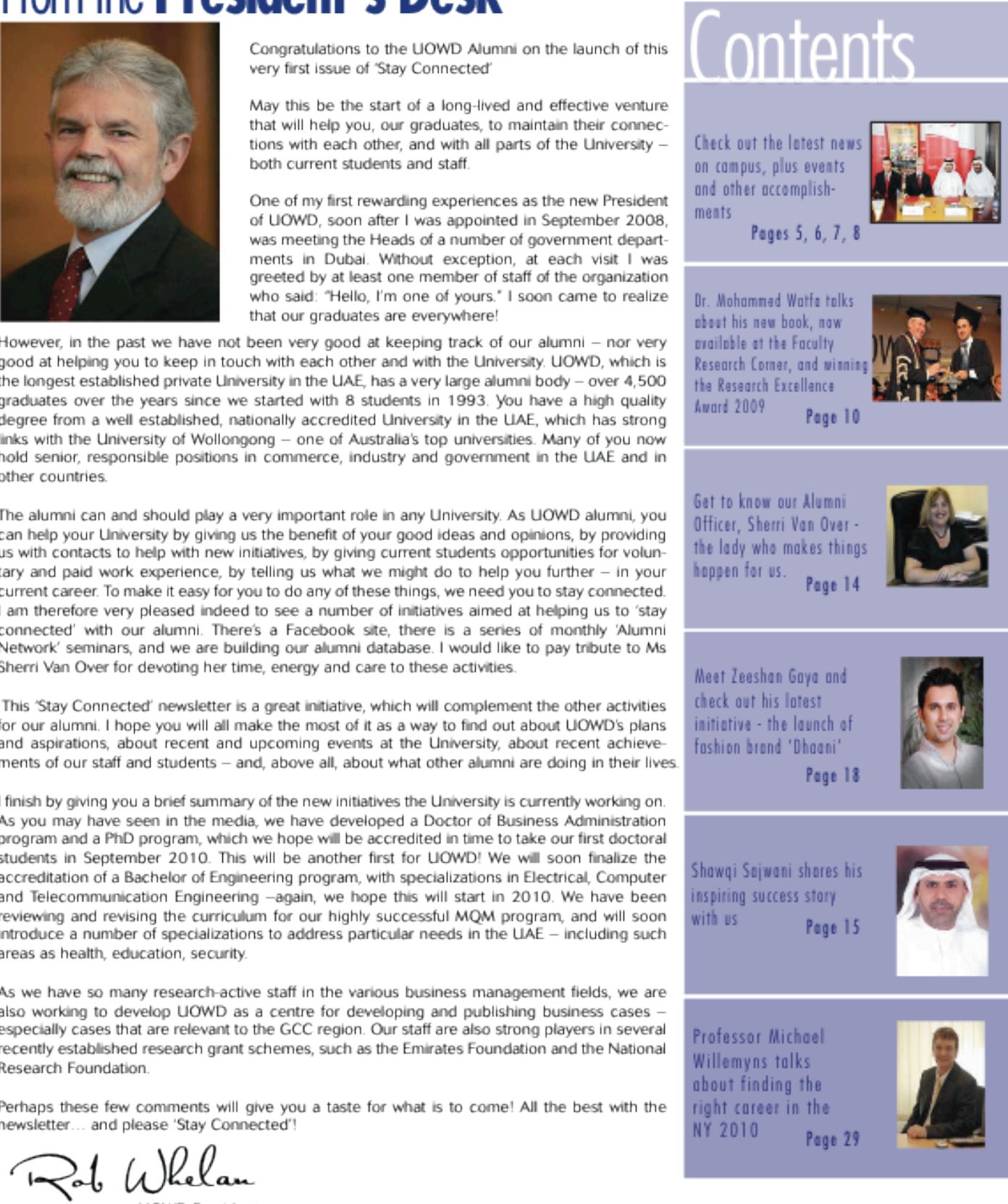

Pages $5,6,7,8$
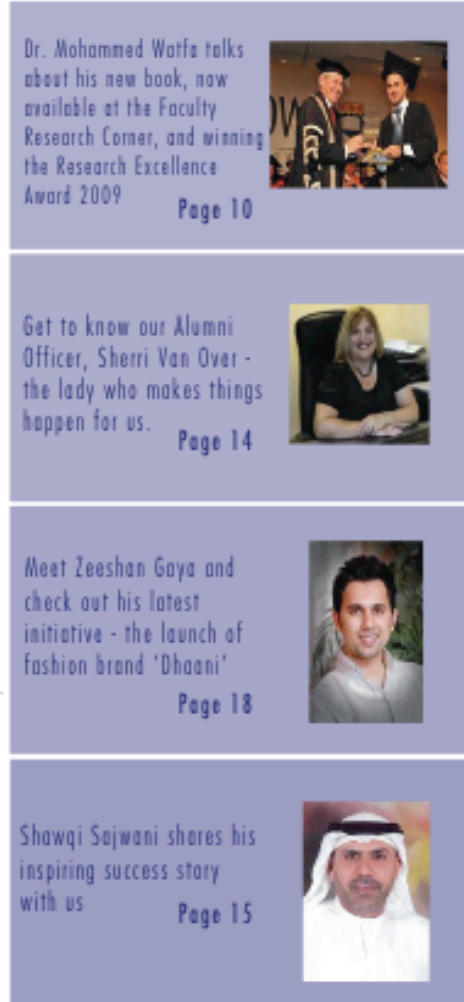

Professor Michoel

Willemyns tolks

about finding the

right career in the NY 2010

Pege 29

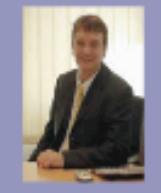

uOWD President

\section{UOWD Alumni Newsletter a wm.uowdubai.ac.0e a University of Wollongong in Dubai}

Exhibit 5: Cover of first issue of the UOWD Alumni Magazine - 'Stay Connected', highlighting key outcomes of the new Strategic Plan, including broadening the disciplines offered and developing research and research training activities. 


\section{Class Notes}

Many challenges face a multinational organisation striving to set up a business in a new location, where different or changing local conditions can create a divergence between the parent company's original expectations for the local branch and the aspirations of the stakeholders in the new location. Management of the local branch can therefore be pulled in different directions by different stakeholders.

This case addresses the management issue of how a newly arrived leader - in an unfamiliar environment with a unique history and complex set of constraints - can refine and implement a new vision for an organisation. It describes the process of developing a new vision, and a set of strategies for achieving it, at the University of Wollongong in Dubai.

The features of this process included: (i) understanding the dynamics of the complex business environment for a private University in the rapidly changing business environment of the UAE; (ii) articulating a clear view of how the organisation might respond to this environmental context; (iii) using this background to frame an inclusive strategic plan review to identify a set of broadly accepted goals; (iv) using the strategic planning process to drive the changes; and (v) gaining the support and involvement of a wide range of stakeholders in pursuing the new vision for the organisation.

This case can be used to explore a number of issues in leadership and management. The following questions can be explored.

- List the various stakeholders in the ongoing development of UOWD. Was each stakeholder given sufficient consideration in the strategic planning process at UOWD? How might this be approached differently?

- How important are stakeholders as distinct elements in the environment of a University? Is the education sector unique or do other sectors have an equivalent range of actors whose preferences should be considered when making strategic decisions? Consider an assignment which requires a comparative study across two or more different sectors to highlight the complexity of stakeholder groups.

- $\quad$ Prior to his arrival in Dubai, Professor Whelan analysed the potential of UOWD to become a comprehensive university with a strong research emphasis. Was this an instance of imposing an external model on an environment not yet ready for it or was sufficient weight given to the local environmental conditions.

- Professor Whelan chose to use a 'public' (but within the University) and inclusive approach to setting and implementing the new direction. What are the potential advantages and disadvantages of a "discreet" analysis and implementation process as opposed to using open public forums?

- Was the implementation of the new direction effective? Was the process sufficiently inclusive or too complicated for the achieving of the intended goals? Does this implementation plan apply more to a public institution than to a private business model? 